\title{
Radial incision and cutting method using a transanal approach for treatment of anastomotic strictures following rectal cancer surgery: a case report
}

\author{
Pramod Nepal, Shinichiro Mori, Yoshiaki Kita, Kan Tanabe, Kenji Baba, Yasuto Uchikado, Hiroshi Kurahara, \\ Takaaki Arigami, Masahiko Sakoda, Kosei Maemura and Shoji Natsugoe
}

\begin{abstract}
Background: Development of an anastomotic stricture following rectal cancer surgery is not uncommon. Such strictures are usually managed by manual or instrumental dilatation techniques that are often insufficiently effective, as evidenced by the high recurrence rate. Various surgical procedures using minimally invasive approaches have also been reported. One of these procedures, endoscopic radial incision and cutting (RIC), has been extensively reported. However, RIC by transanal minimally invasive surgery (TAMIS) is yet to be reported. We here report a novel application of TAMIS for performing RIC for anastomotic rectal stenosis.

Case presentation: A 67-year-old man had suffered from constipation for 6 years after undergoing low anterior resection for stage II rectal cancer 7 years ago. Colonoscopy showed a 1-cm diameter stricture in the lower rectum. Balloon dilatation was performed many times because of repeated recurrences. Thus, surgical management was considered and the stricture was successfully excised via a RIC method using a TAMIS approach. Postoperatively, the patient had minimal leakage that resolved with conservative treatment.
\end{abstract}

Conclusions: A RIC method using a TAMIS approach is an effective minimally invasive means of managing anastomotic strictures following rectal cancer surgery.

Keywords: Rectal stenosis, Rectal stricture, Anastomosis, Radial incision and cutting, Transanal minimally invasive surgery, Case report

\section{Background}

Lower rectal surgeries with colorectal or coloanal anastomoses for rectal cancer are complicated by benign anastomotic strictures in up to $22 \%$ of patients [1]. Obesity, irradiation, abscess formation, incomplete "doughnut" construction, low-lying anastomosis, use of a stapling device, postoperative leakage, and pelvic infection are reportedly factors related with anastomotic leakage $[1,2]$. Digital or instrumental dilatation techniques and endoscopic balloon dilatation (EBD) are currently the preferred treatment methods for such strictures.

\footnotetext{
* Correspondence: morishin@m3.kufm.kagoshima-u.ac.jp Department of Digestive Surgery, Breast and Thyroid Surgery, Graduate School of Medicine, Kagoshima University, Sakuragaoka 8-35-1, Kagoshima 890-8520, Japan
}

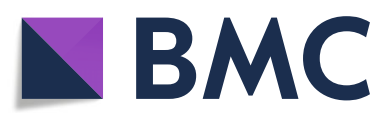

(c) The Author(s). 2019 Open Access This article is distributed under the terms of the Creative Commons Attribution 4.0 International License (http://creativecommons.org/licenses/by/4.0/), which permits unrestricted use, distribution, and reproduction in any medium, provided you give appropriate credit to the original author(s) and the source, provide a link to the Creative Commons license, and indicate if changes were made. The Creative Commons Public Domain Dedication waiver (http://creativecommons.org/publicdomain/zero/1.0/) applies to the data made available in this article, unless otherwise stated. recurrence rate is high and repeated dilatations may be required [3].

Conventional surgical approaches to treatment are invasive and do not eliminate the risk of recurrence [4]. In 2007, Asada et al. reported radial incision and cutting (RIC), a new technique with promising results [5]. This procedure is feasible, safe, and effective for esophagogastric anastomotic strictures that are refractory to repeated EBD [6]. Here, we discuss a patient with a benign rectal anastomotic stricture following low anterior resection (LAR) that was managed with RIC using a transanal minimally invasive surgery (TAMIS) approach in our university hospital. Although RIC via an endoscopic approach has been reported for treatment of both 
esophageal and colorectal anastomotic strictures, RIC using a TAMIS approach has not been reported yet. We consider that TAMIS provides a superior operative field, enabling precise incision and adequate excision of such a stricture and consequently better prevents recurrence.

\section{Case presentation}

A 67-year-old man presented with complains of constipation for 6 years. He had undergone LAR for stage II rectal cancer 7 years ago. Postoperatively, he had developed an anastomotic stricture consequent to postoperative leakage and underwent endoscopic balloon dilatation. The symptoms relapsed and after 2 years of first balloon dilatation, it was repeated again. The patient needed the treatment with laxatives for stool softening. Nonetheless, symptoms did not resolve completely and balloon dilatation had to be repeated again with minimal success. Eventually, the patient was referred to our department for surgical management. Then, RIC using TAMIS approach considered the procedure of choice.

The patient had an unremarkable physical and systemic examination. His BMI was $24.07 \mathrm{~kg} / \mathrm{m}^{2}$. Medical history revealed hypertension, dyslipidemia, osteoarthritis of the knee, and a past history of pulmonary tuberculosis. The family history was irrelevant. Colonoscopy showed a $1-\mathrm{cm}$ diameter stricture in the lower rectum (Fig. 1a) through which an endoscope with an external diameter of $9.9 \mathrm{~mm}$ could be passed with resistance.
Preoperative computed tomography-colonography showed narrowing in the lower rectum (Fig. 1b), as did magnetic resonance imaging of the pelvis, which showed rectal narrowing accompanied by muscular thickening (Fig. 1c, d).

The patient was placed in a modified lithotomy position and the anus dilated with a self-retaining anal retractor (Lone Star Retractor; Cooper Surgical, Trumbull, CT, USA). A transanal access device (GelPOINT Path; Applied Medical, Rancho Santa Margarita, CA, USA) was introduced (Fig. 2). A pneumorectum was maintained at $12 \mathrm{mmHg}$ with carbon dioxide using an AirSeal platform (AirSeal System; Conmed, Utica, NY, USA), and conventional laparoscopic instruments were used [7]. A 1-cm stricture was located in the lower rectum (Fig. 3a) and full-thickness incisions made parallel to the axis of the rectum at the 9 o'clock (Fig. 3b) and 3 o'clock positions of the stricture (Fig. 3c). The stricture wall was then cut from 9 o'clock to 7 o'clock and 3 o'clock to 6 o'clock (Fig. 3d). After intraluminal lavage with saline, hemostasis was secured. The defect was then closed with 3-0 V-Loc suture (Medtronic, Minneapolis, MN, USA), as shown in Fig. 4a. On the 13th post-operative day, rectal perforation was detected in colonoscopy that resolved with conservative treatment (Fig. 4b). The perforation had sealed off when inspected on 26th post-operative day (Fig. 4c). The patient was discharged on the 33rd post-operative day, 36 days after the admission and
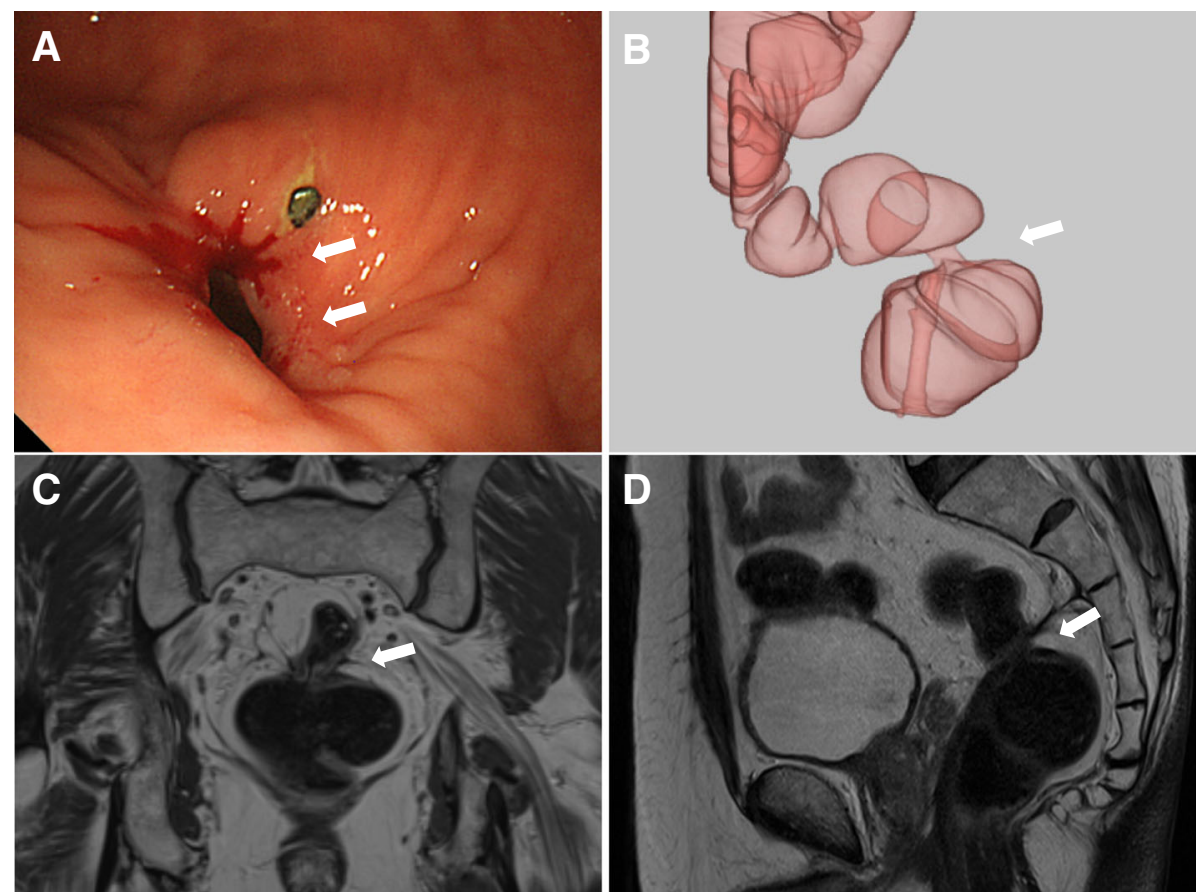

Fig. 1 a Colonoscopy image showing a stricture in the lower rectum (white arrow). An endoscope of external diameter $9.9 \mathrm{~mm}$ could be passed, with resistance, through this stenosis. b Preoperative computed tomography-colonography image showing narrowing of the rectum at the stenosis (black arrow). c, d Magnetic resonance images showing rectal narrowing accompanied by muscular thickening (yellow arrow) 


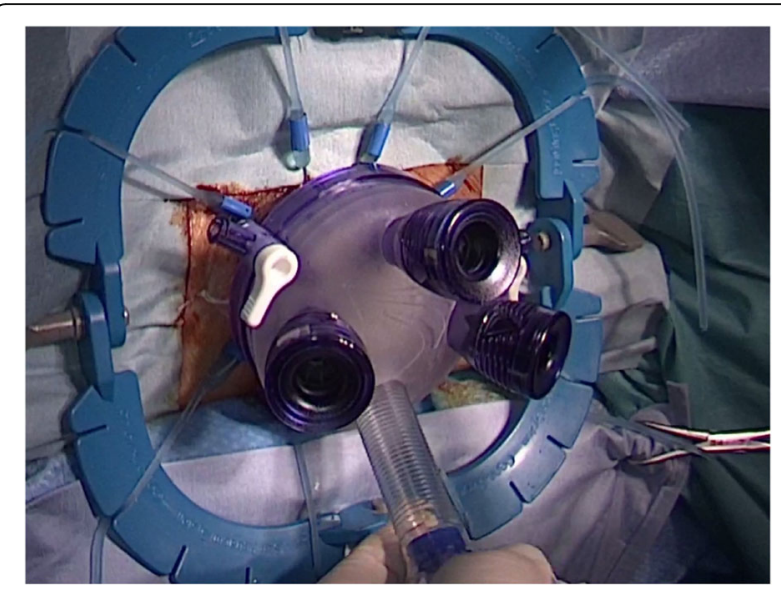

Fig. 2 The anal orifice was dilated and a transanal access device was introduced

attended for regular follow-up without experiencing additional complications. One year after surgery, the patient no longer required medication for constipation, and endoscopic examination showed no stricture (Fig. 4d).

\section{Discussion and conclusions}

Endoscopic balloon dilatation is still the treatment of first choice for benign anastomotic strictures; however, the subsequent recurrence rate is high, often necessitating repeated dilatations [3]. This can lead to severe fibrotic changes in the stricture and ultimate treatment failure [6]. Additionally, there is a high risk of perforation after EBD associated with uncontrolled stretching, inadequate visualization of the entire stricture, and various technical difficulties [8,9]. Short strictures can often easily be managed with EBD; however, short strictures that are resistant to EBD or larger strictures require surgical treatment [10]. Transabdominal repeat surgery, an ileal pouch advancement procedure, and construction of a permanent stoma are too invasive and should be the last resort. Less invasive options such as stent placement, transanal stricturoplasty, stapler stricturoplasty, resection using transanal endoscopic microsurgery (TEM), and endoscopic transanal resection (ETAR) by urologic resectoscopy are all preferable. An endoscopic electrocautery incision (EECI) technique, in which the stricture is incised radially and the RIC procedure, in which further radial cuts are made in the stricture after incision are additional recently described minimally invasive options $[3,6,10,11]$.

RIC was originally developed for treating esophageal strictures that are resistant to repeated dilatations [5] and was later also used for rectal strictures [12]. The outcomes of RIC are comparable or even superior to those of EECI. According to a review article by Jain et al., the long-term success rate after RIC is $95.8 \%$,
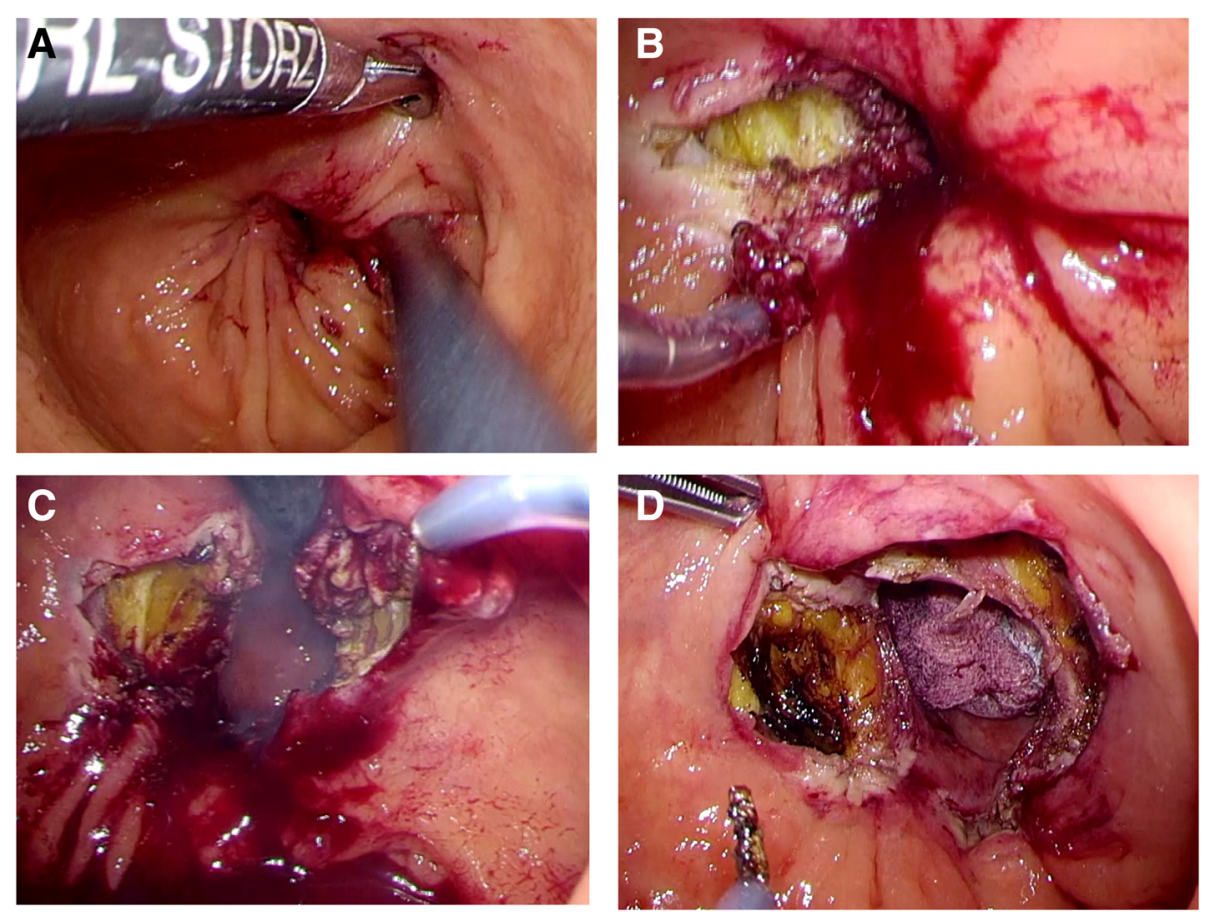

Fig. 3 Intraoperative photographs. a The stricture has been located in the lower rectum. $\mathbf{b}$ A full-thickness incision parallel to the axis of the rectum has been made at the 9 o'clock position of the stricture. $\mathbf{c}$ A similar incision has been made at the 3 o'clock position. $\mathbf{d}$ The stricture wall was been cut from 9 o'clock to 7 o'clock and 3 o'clock to 6 o'clock 

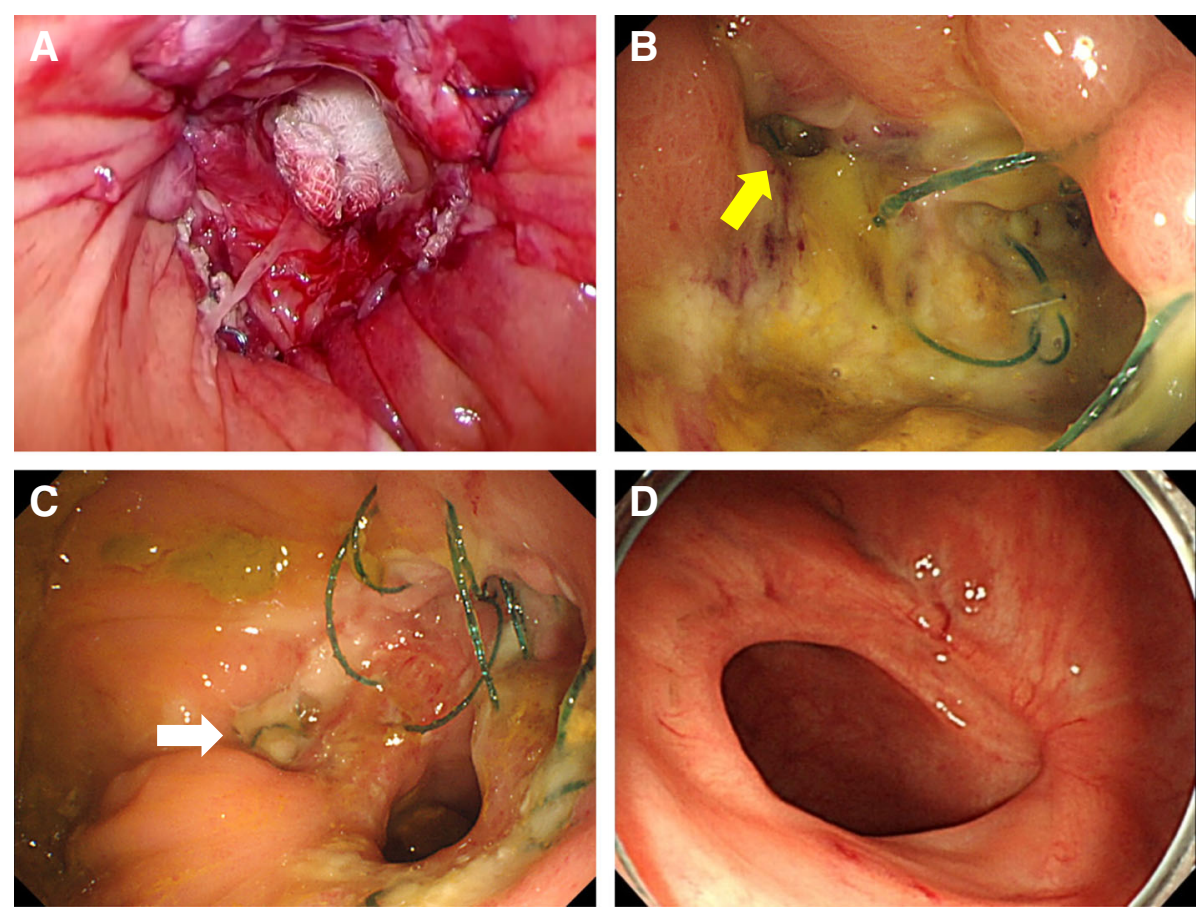

Fig. 4 a Operative site at the end of surgery. b Perforation (yellow arrow) seen in colonoscopy on the 13th post-operative day. c The perforation had sealed off when inspected on 26th post-operative day (white arrow). $\mathbf{d}$ Endoscopic image 1 year after surgery; no stricture is detectable

whereas that after EECI alone is $95.2 \%$, and after EECI with balloon dilatation $87.8 \%$ [8]. The stricture recurrence rate following endoscopic electrocautery with RIC was $0 \%$, following EECI alone was $4.8 \%$ and following EECI with balloon dilatation was $12.5 \%$ [8]. This review article reports no procedure-related perforation in 186 patients who underwent EECI [8]. Whereas perforation rates of $3.1 \%$ and $4.6 \%$ following EBD are reported in the study by Park and et al. and Kozarek RA respectively $[13,14]$. Thus, EECI techniques have a lower perforation rate than EBD.

We believe that a transanal approach by TEM and TAMIS provides a superior operative field that enables greater precision and more complete resection of a stricture than an endoscopic approach. TEM enables controlled excision of the whole fibrotic ring under full vision, which is cardinal for preventing recurrences [15]. Baatrup et al. experienced no perforations following the excision of rectal strictures by using TEM in six subjects. In one patient, the procedure was converted to balloon dilatation due to very low position of the stricture [15]. However, TEM has not been universally adopted by colorectal surgeons because of the significant cost of the required highly specialized instrumentation and steep learning curve [16]. TAMIS, a hybrid of TEM and single-port laparoscopy, was first reported in 2010 by Atallah et al., who concluded that TAMIS is a feasible alternative to TEM and provides the same benefits at a fraction of the cost [17]. Although the idea of TAMIS is not entirely novel and is based on the similar principle of transanal stricturoplasty of TEM, it is being increasingly adopted, thanks to the requirement for only ordinary laparoscopic instruments and experience with single-port laparoscopic surgery. TAMIS provides minimally invasive access for utilizing the RIC method and ensures precise incisions in a post-rectal surgery anastomotic stricture. It also provides a new strategy for managing recurrent anastomotic stenosis after the use of manual or instrumental dilatation techniques. We were unable to find any reports of using the RIC method with TAMIS approach for benign rectal strictures. Further large prospective studies are needed.

In conclusion, the RIC procedure using a TAMIS approach can be used for minimally invasive management of anastomotic strictures following rectal cancer surgery and is a promising means of managing recurrent stenosis.

\section{Abbreviations}

EBD: Endoscopic balloon dilatation; EECl: Endoscopic electrocautery incision; ETAR: Endoscopic transanal resection; LAR: Low anterior resection; RIC: Radial incision and cutting; TAMIS: Transanal minimally invasive surgery;

TEM: Transanal endoscopic microsurgery

\section{Acknowledgements}

We appreciate the contributions of all the surgeons, coworkers, and friends involved in this study and thank the editors and reviewers for their help with this manuscript. We also thank Dr. Trish Reynolds, MBBS, FRACP, from Edanz Group (www.edanzediting.com/ac) for editing a draft of this manuscript. 


\section{Funding}

No funding was received specifically for this study.

\section{Availability of data and materials}

The datasets used and/or analyzed during the current study are available from the corresponding author on reasonable request.

\section{Authors' contributions}

PN and SM conceived of the study, designed it, and acquired the data. YK, $K T, K B, Y U, H K, T A, M S$, and KM participated in the design of the study, coordination, and analysis of the data. PN drafted the manuscript. SN participated in the manuscript preparation and critical revision. All authors read and approved the manuscript.

\section{Ethics approval and consent to participate}

Written consent for participation was obtained. No ethics approval was required.

\section{Consent for publication}

Written consent for publication of images and necessary data was obtained.

\section{Competing interests}

The authors declare that they have no competing interests.

\section{Publisher's Note}

Springer Nature remains neutral with regard to jurisdictional claims in published maps and institutional affiliations.

Received: 6 November 2018 Accepted: 7 March 2019

Published online: 14 March 2019

\section{References}

1. Luchtefeld MA, Milsom JW, Senagore A, Surrell JA, Mazier WP. Colorectal anastomotic stenosis. Results of a survey of the ASCRS membership. Dis Colon Rectum. 1989:32:733-6.

2. Schlegel RD, Dehni N, Parc R, Caplin S, Tiret E. Results of reoperations in colorectal anastomotic strictures. Dis Colon Rectum. 2001:44:1464-8.

3. Kraenzler A, Maggiori L, Pittet O, Alyami MS. Prost à la Denise J, Panis Y. Anastomotic stenosis after coloanal, colorectal and ileoanal anastomosis: what is the best management? Color Dis. 2017;19:90-6.

4. Bravi I, Ravizza D, Fiori G, Tamayo D, Trovato C, De Roberto G, et al. Endoscopic electrocautery dilation of benign anastomotic colonic strictures: a single-center experience. Surg Endosc. 2016;30:229-32.

5. Asada $Y$, Muto M. New treatment for refractory stricture of the digestive tract: Radical Incision and Cutting (RIC) [abstract]. Gastrointest Endosc. 2007; 65:AB279.

6. Muto M, Ezoe Y, Yano T, Aoyama I, Yoda Y, Minashi K, et al. Usefulness of endoscopic radial incision and cutting method for refractory esophagogastric anastomotic stricture (with video). Gastrointest Endosc 2012;75:965-72

7. Nepal P, Mori S, Kita Y, Tanabe K, Baba K, Uchikado Y, Kurahara H, Arigami T, Sakoda M, Maemura K, Natsugoe S. Management of a case of high-risk gastrointestinal stromal tumor in rectum by transanal minimal invasive surgery. World J Surg Oncol. 2018;16(1):165.

8. Jain D, Sandhu N, Singhal S. Endoscopic electrocautery incision therapy for benign lower gastrointestinal tract anastomotic strictures. Ann Gastroenterol. 2017:30:473.

9. Di ZH, Shin JH, Kim JH, Song HY. Colorectal anastomotic strictures: treatment by fluoroscopic double balloon dilation. J Vasc Interv Radiol. 2005;16:75-80.

10. Garcea G, Sutton CD, Lloyd TD, Jameson J, Scott A, Kelly MJ. Management of benign rectal strictures. Dis Colon Rectum. 2003;46:1451-60.

11. Polese L, Vecchiato M, Frigo AC, Sarzo G, Cadrobbi R, Rizzato R, et al. Risk factors for colorectal anastomotic stenoses and their impact on quality of life: what are the lessons to learn? Color Dis. 2012;14:124-8.

12. Osera $\mathrm{S}$, Ikematsu $\mathrm{H}$, Odagaki $\mathrm{T}$, Oono $\mathrm{Y}$, Yano $\mathrm{T}$, Kobayashi A, et al. Efficacy and safety of endoscopic radial incision and cutting for benign severe anastomotic stricture after surgery for lower rectal cancer (with video). Gastrointest Endosc. 2015:81:770-3.
13. Park CH, Yoon JY, Park SJ, Cheon JH, Kim TI, Lee SK, Lee YC, Kim WH, Hong SP. Clinical efficacy of endoscopic treatment for benign colorectal stricture: balloon dilatation versus stenting. Gut Liver. 2015;9(1):73.

14. Kozarek RA. Hydrostatic balloon dilation of gastrointestinal stenoses: a national survey. Gastrointest Endosc. 1986;32(1):15-9.

15. Baatrup G, Svensen R, Ellensen VS. Benign rectal strictures managed with transanal resection - a novel application for transanal endoscopic microsurgery. Color Dis. 2010;12:144-6.

16. Maslekar S, Pillinger SH, Sharma A, Taylor A, Monson JR. Cost analysis of transanal endoscopic microsurgery for rectal tumours. Color Dis. 2007;9:229-34

17. Atallah S, Albert M, Larach S. Transanal minimally invasive surgery: a giant leap forward. Surg Endosc. 2010;24:2200-5.

\section{Ready to submit your research? Choose BMC and benefit from:}

- fast, convenient online submission

- thorough peer review by experienced researchers in your field

- rapid publication on acceptance

- support for research data, including large and complex data types

- gold Open Access which fosters wider collaboration and increased citations

- maximum visibility for your research: over $100 \mathrm{M}$ website views per year

At $\mathrm{BMC}$, research is always in progress.

Learn more biomedcentral.com/submissions 